\title{
Results from a Survey of Faculty Adoption of Process Oriented Guided Inquiry Learning (POGIL) in Computer Science
}

\author{
Helen $\mathrm{H}$. Hu \\ Westminster College \\ Salt Lake City, Utah, USA \\ hhu@westminstercollege.edu
}

\author{
Clifton Kussmaul \\ Muhlenberg College \\ Allentown, Pennsylvania, USA \\ kussmaul@muhlenberg.edu
}

\author{
Brian Knaeble \\ Westminster College \\ Salt Lake City, Utah, USA \\ bknaeble@westminstercollege.edu
}

\author{
Chris Mayfield \\ James Madison University \\ Harrisonburg, Virginia, USA \\ mayfiecs@jmu.edu
}

\author{
Aman Yadav \\ Michigan State University \\ East Lansing, Michigan, USA \\ ayadav@msu.edu
}

\begin{abstract}
This paper presents an analysis of CS faculty perceptions of the benefits of POGIL, the obstacles to POGIL adoption, and opportunities for professional development. Participants strongly agreed that with POGIL, students are more engaged and active, develop communication and teamwork skills, and have better learning outcomes. The largest perceived obstacle was lack of preparation time; other obstacles included availability of relevant POGIL activities and pressure to cover more content. Participants expressed a desire for further training and mentoring beyond workshops. Our data analysis also considers bivariate associations and interactions. The results should help to improve professional development for CS faculty adopting evidence-based strategies, and thereby help more CS students to be successful.
\end{abstract}

\section{INTRODUCTION}

Process Oriented Guided Inquiry Learning (POGIL) is an evidence-based, student-centered pedagogy that focuses on the simultaneous development of content knowledge and process skills (such as critical thinking, problem solving, teamwork, and written/oral communication). Students work in learning teams on carefully designed activities that guide them to construct course concepts. POGIL incorporates techniques that have been shown to retain students from underrepresented groups, and it has been shown to be highly effective in chemistry, biology, and many other disciplines. This paper presents results and analysis from a survey of CS faculty who have attended POGIL training and/or adopted POGIL in their classrooms. The survey is intended to explore CS faculty perceptions of the benefits of POGIL, the obstacles to POGIL adoption, and options for professional development and support.

Permission to make digital or hard copies of all or part of this work for personal or classroom use is granted without fee provided that copies are not made or distributed for profit or commercial advantage and that copies bear this notice and the full citation on the first page. Copyrights for components of this work owned by others than the author(s) must be honored. Abstracting with credit is permitted. To copy otherwise, or republish, to post on servers or to redistribute to lists, requires prior specific permission and/or a fee. Request permissions from permissions@acm.org.

ITiCSE '16, July 11-13, 2016, Arequipa, Peru.

(C) 2016 Copyright held by the owner/author(s). Publication rights licensed to ACM. ISBN 978-1-4503-4231-5/16/07 . \$15.00

DOI: http://dx.doi.org/10.1145/2899415.2899471
The ICAP framework [5] describes how learning outcomes tend to improve as student engagement progresses from Passive (read, watch) to Active (copy, rehearse) to Constructive (explain, generate, reflect) to Interactive (discuss, debate). Thus, in more effective strategies, students tend to work together to construct understanding. A variety of evidencebased strategies have been explored recently in CS education, including Cooperative Learning [1], Pair Programming [27], Pedagogical Code Reviews [18], Peer Instruction [22, 28], Peer-Led Team Learning [9, 15] and Studio-Based Learning [19]. Many of these strategies include elements that help close the achievement gap for students from underrepresented groups (e.g., [4]).

Unfortunately, very few faculty seek out and consistently adopt evidence-based strategies. CS faculty rarely $(<10 \%)$ search methodically in the literature; most changes occur without outside sources, or via personal interactions [8]. Professional development often increases knowledge about innovations, but it rarely provides incentives or ongoing support [3]. A survey of 700 physics faculty found that only $23 \%$ currently used $3+$ evidence-based strategies, $12 \%$ were unfamiliar with any, $16 \%$ had some knowledge but had never tried one, and $23 \%$ had tried one and stopped [13]. A survey of 400 US engineering faculty found that fidelity of implementation ranged from $11-80 \%$ [2]; i.e., faculty are likely to omit critical components.

Henderson et al. [13] conclude that: “... current change strategies seem to do a reasonably good job of helping faculty develop knowledge and motivation to try [evidence-based strategies]... It may be more fruitful to focus on those who discontinue use..." Thus, we need to better understand how to encourage and support faculty to adopt and persist with evidence-based strategies. Effective approaches for doing so are aligned with or seek to change beliefs, involve longterm interventions (at least one semester), and approach education as a complex system [12]. In many cases, evidencebased strategies cannot be adopted directly; they must be adapted and customized for particular institutions, student populations, and faculty [20].

Compared to other strategies, POGIL is more explicitly constructive and interactive because of the ways its activities are designed and facilitated. POGIL activities incorporate models (e.g., figures, tables, equations, sample code) and 
a sequence of critical thinking questions that guide students to explore the models, invent key concepts, and apply their new understanding [10]. The models and critical thinking questions must be robust and well-aligned, and they distinguish POGIL from simply having students complete worksheets in small groups [24]. In a POGIL classroom, selfmanaged teams of 3-4 students work together and discuss problems to improve understanding for all team members. At the same time, instructors purposefully help students to develop process skills such as critical thinking, problem solving, and teamwork. The instructor's role shifts from disseminator of information ("sage on the stage") to facilitator of learning ("guide on the side"), who continually assesses how and when to offer additional guidance as the teams work [10].

For example, instructors may use the following POGIL activity on the first day of CS 1 to show students that CS is about analyzing problems and solutions, not just programming. The first model lists instructions for a two-player game where Player A picks a number from 0 to 100 and then answers "too high" or "too low" in response to Player B's guesses. Critical thinking questions prompt the student teams to play the game (explore), and then to identify a set of strategies (algorithms) for player B, such as "guess at random", "count up by 1s", or "split the range in half". As the teams work, the instructor listens, answers questions, and prompts teams to improve their descriptions. After a few minutes, the instructor has each team describe a strategy to the class. Next, teams rank their strategies by number of guesses and how hard they are to describe, and compare the rankings to discover the common tradeoff between speed and difficulty (invent). Teams then identify other situations with similar tradeoffs, and share them with the class (apply). In the next cycle, the strategies are the model, which teams explore to find the maximum (worst case) and average number of guesses for each strategy, leading them to invent $\mathrm{O}($ )-style complexity analysis, which they then apply in homework.

POGIL was originally studied in college general chemistry courses, where it was found both to improve student performance and significantly decrease DFW grades (e.g., $[7,24,25])$. Hanson [10] summarizes the student outcomes for POGIL generally described in the literature: (1) attrition is lower; (2) content mastery is greater; (3) students prefer POGIL; (4) students have more positive attitudes about the course and the instructors; and (5) learning skills appear to improve. POGIL has been used across STEM disciplines including engineering [6, 26], mathematics [23], and physiology [29]; and at a variety of institutions including minority-serving and community colleges (e.g., [11, 14]).

POGIL is especially appropriate for CS, because it shifts student attention away from issues like language syntax and towards conceptual understanding. After converting a CS1 course to POGIL, one author saw pass rates increase for female students but not males [17]. A POGIL CS Principles course increased student interest in taking additional CS courses [16]. In a software project course, POGIL activities helped students to understand the importance of communication in real software projects [21]. A CS1 course with 29 POGIL-like cooperative activities yielded exam scores that were significantly higher overall and by major, ethnicity, and gender, compared to a traditional course [1].

However even for experienced faculty, POGIL requires significant effort to develop or adapt materials and to implement effective classroom facilitation techniques. Founded in
2005, the POGIL Project (https://pogil.org) is a nonprofit 501(c)3 that organizes regional workshops and develops classroom resources. The Project offers a curriculum of sixteen 90-minute sessions and a pool of trained workshop facilitators, using evidence-based propagation practices. Half- and full-day workshops offered throughout the year introduce basic concepts and practices to help instructors decide how to implement POGIL. Each summer, the Project organizes interdisciplinary, three-day POGIL regional meetings.

In the computer science education community, POGIL is relatively new but growing quickly. The CS-POGIL Project (see http://cspogil.org) has fostered a community of practice within CS through conference sessions and workshops, financial support for CS faculty to attend summer workshops on POGIL (25 faculty, including 4 at community colleges), and online discussions. At the time of writing, CS faculty have authored over 200 POGIL activities for a variety of CS undergraduate courses. These sets of activities make it easier for other CS faculty to adopt POGIL.

\section{METHODS}

The authors' personal experiences adopting POGIL and training and supporting other faculty, as well as the literature on effective propagation and professional development, has suggested that existing POGIL workshop experiences are valuable but often insufficient, and that faculty could benefit from additional support, such as advanced or disciplinespecific workshops, enhanced classroom materials, and a community of practice. In order to accurately gauge faculty perceptions, we surveyed CS faculty involved in POGIL to explore their views about the benefits of POGIL, the obstacles to POGIL adoption, and options for professional development and support.

In December 2015, we invited 65 CS faculty from the United States (including both college and secondary teachers) to complete an online survey. Note that this is not a representative sample of all CS faculty, since we only invited faculty who had participated in POGIL training and/or taught using POGIL. Our survey (see https://goo.gl/forms/yov406fywh) was adapted from a national survey of science faculty's perceptions of implementing case-based instruction in undergraduate science courses [30]. Specifically, our survey asked about (a) demographics for the instructor and institution, (b) perceptions of POGIL's effect on students' experiences, (c) perceptions of potential obstacles to adopting POGIL, and (d) perceptions of what support would be helpful for CS faculty to adopt POGIL.

\subsection{Demographics}

The study participants were 32 CS instructors (49\% response rate) from junior high (1), high schools (3), community colleges (3), and 4-year institutions (25). A majority of respondents $(\mathrm{n}=22)$ had attended a three-day POGIL Regional Meeting; these were referred to below as high training. Those who had not $(n=10)$ were referred to as low training; of them, five had attended a one-day introductory POGIL workshop, and five had less than one day of training. Of the 32 respondents, 9 used POGIL at least biweekly, and another 11 used POGIL 3-6 times per semester. In the analyses below, high use refers to those who used POGIL at least 3 times per semester $(n=20)$. Those who used POGIL fewer than three times per semester $(n=12)$ are classified as low use, and this group includes those who had never used POGIL, 
and one user who had discontinued use of POGIL. In their classrooms, instructors used POGIL activities from multiple sources; 15 used activities shared directly by another CS instructor, 16 used activities from the CS-POGIL website (http://cspogil.org), and 23 developed their own activities.

\subsection{Data Analysis}

There were ten survey questions relating to POGIL's effectiveness, six survey questions relating to obstacles to adoption, and five survey questions relating to the helpfulness of additional support for instructors adopting POGIL. The effectiveness questions had five response options (5:strongly agree, 4:agree, 3:neutral, 2:disagree, and 1:strongly disagree), and also an N/A option for those who had not used POGIL. The obstacle questions had five response options (5:very strong, 4:strong, 3:middle, 2:somewhat, and 1:not at all) for the strength of each obstacle. The support questions had five response options (5:extremely helpful, 4:very helpful, 3:somewhat helpful, 2:slightly helpful, and 1:not at all). We performed an exploratory, descriptive analysis on the resulting data using $R$.

When describing data for a single variable, we report proportions without specifying confidence intervals, as we were not inferring to any well-defined population. We occasionally use the numerical correspondences from the previous paragraph to compute means. When describing data for pairs of variables we utilized the Wilcoxon rank-sum test for independent samples and the Wilcoxon signed-rank test for paired samples, as the response options were naturally ordered but not naturally spaced. The test statistics for the Wilcoxon rank-sum test and signed-rank test are denoted with $\mathrm{W}$ and $\mathrm{V}$, respectively. In both cases we considered $\mathrm{p}$ values less than .05 as statistically significant.

Our stated statistics should be interpreted with caution. The Wilcoxon $\mathrm{p}$ values were not exact because we had repeated values, and small sample size may be to blame for lack of significance in some cases, especially when we restricted our attention to demographic subsamples. Concern about multiple comparisons is more valid with our stated $\mathrm{W}$ statistics than with our V statistics. Also, a small group of respondents may be responsible for a statistically significant result, and we recommend viewing graphs in addition to stated statistics. Interpretation of observed associations is provided in the text of Section 3.

\section{RESULTS}

\subsection{Perceived Effectiveness}

Figure 1 shows how strongly participants agreed with each statement, sorted by agreement. The $\mathrm{x}$-axis of all figures is the number of respondents. There is strong agreement that students were more engaged $(92 \%)$ and more active $(88 \%)$. One respondent wrote "the most noticeable change is the increased engagement."

With regard to process skills, participants also agreed that students develop stronger skills in communication (84\%) and teamwork $(85 \%)$. One respondent wrote "students enjoy showing each other the concepts and how to understand them", while another noted "My students develop peer-topeer relationships that lead to more learning opportunities, very important on a campus with $90 \%$ commuter students. In addition, their communication skills improve and this teaching method opens a dialog between professor and students."

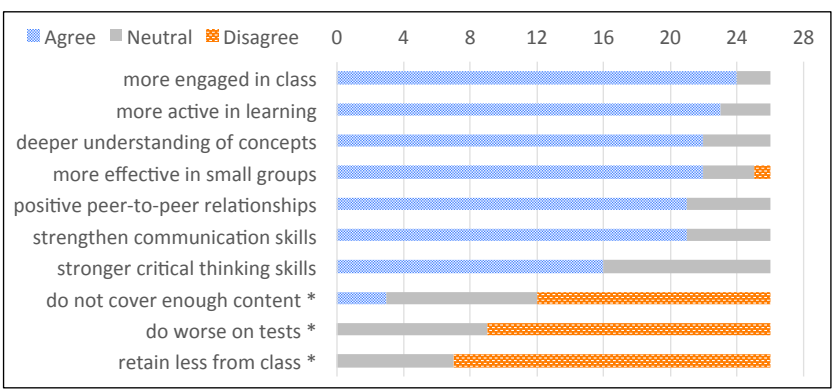

Figure 1: Perceptions of POGIL effectiveness measured by 26 POGIL instructors' agreement with 7 positive statements and 3 negative $(*)$ statements.

A third respondent highlighted that the better peer-to-peer relationships affect other assignments: "The students form stronger relationships with their peers and I see more collaboration outside of the POGIL assignments."

Faculty also perceived an increase in student learning outcomes. Participants agreed that students developed deeper understanding (85\%). There was also strong agreement that students did not retain less $(73 \%)$, students did not do worse on tests $(65 \%)$, and students did not feel they were covering too little content (54\%). Some faculty appeared to tie this increase in student learning outcomes to increased engagement and collaboration: "Students are better able to make sense of the more confusing topics by being active in their own discovery and having ownership in what they are learning." Other free response answers suggest additional possible reasons: "POGIL activities helps to focus effort on the material that needs it", "students are developing conclusions instead of me telling them the conclusions", and "Students retain more, develop a vocabulary for discussing CS".

While we did not ask directly whether students perceived the same positive effect on learning outcomes, some faculty shared their experiences. One faculty wrote: "While I think students are learning more, they don't seem to think so." Another respondent found the reverse: "Student feedback from my CS 1 class was that they enjoyed the POGIL activities, and that they helped them better understand the content. They also felt the somewhat more conceptual approach helped them when they did the actual programming."

\subsection{Obstacles to Adoption}

In the next part of the survey, participants were asked to respond to six items to "indicate the degree to which you experienced these potential obstacles". Figure 2 summarizes participant responses, ordered by increasing percentage experiencing the obstacle. Of the six obstacles surveyed, the most frequently perceived obstacle was lack of preparation time (94\% experiencing some difficulty, including 19\% experiencing very strong difficulty). Availability of relevant POGIL activities (88\%, including $6 \%$ very strong) and pressure to cover content $(78 \%$, including $6 \%$ very strong) were also obstacles for many instructors. $68 \%$ respondents experienced resistance from students (none very strong), whereas only a quarter experienced resistance from colleagues and administrators (3\% very strong) as obstacles to adopting POGIL. $72 \%$ experienced difficulty adapting to teaching style $(3 \%$ very strong). 


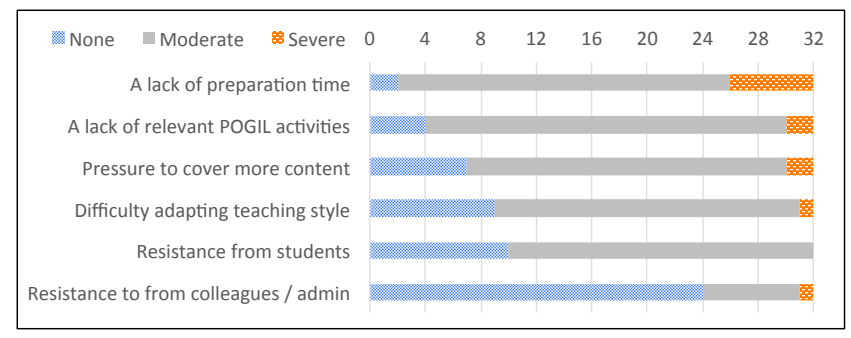

Figure 2: Obstacles to POGIL adoption $(\mathrm{n}=32)$

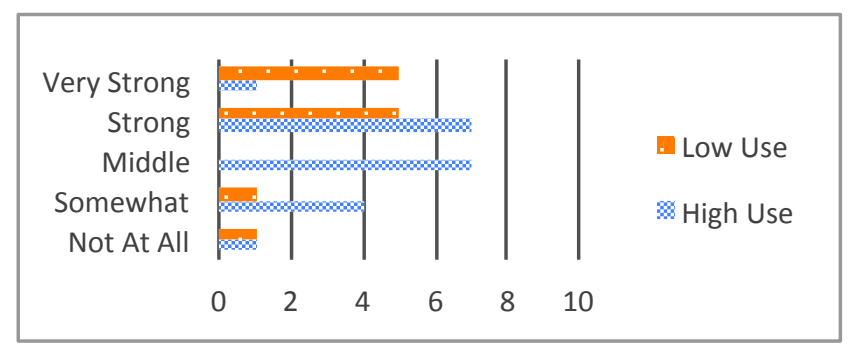

Figure 3: Lack of preparation time as a perceived obstacle to POGIL adoption $(n=32)$. Low use may be due to a perceived lack of preparation time.

For the "lack of preparation time", we found a significant association with POGIL use $(\mathrm{W}=61.5, \mathrm{p}=.019)$, shown in Figure 3. Specifically, low use respondents $(\mathrm{n}=12$, mean $=4.0)$ experienced this obstacle more strongly than high use $(n=20$, mean $=3.15$ ). This suggests that low use respondents overestimate the preparation time required, or that there were economies of scale as the level of use increases. $44 \%$ of the respondents mentioned time in their answers to the freeresponse question about their main obstacles in adopting or implementing POGIL. While many were vague (e.g., "time") or cited lack of time to prepare, others seemed to be more concerned with classroom time, specifically "balancing lab time with POGIL time". Similarly, another instructor explained "It is challenging to provide enough coding practice time in-class, and POGIL takes time, some of which is coding." While the survey asked about "pressure to cover more content", some faculty may not have interpreted this pressure equivalent to lack of classroom time. Future surveys should include an additional question about classroom time.

$88 \%$ of the respondents cited "a lack of relevant POGIL activities" as an obstacle to POGIL adoption, which seems connected to lack of preparation time. One respondent pointed out "Finding, selecting, and integrating existing activities may take as much time as authoring a custom activity. The advantage of using an existing activity is that it may be better designed than one I wrote just in time for class." Some people's concern about a lack of relevant POGIL activities may lesson with more POGIL use $(\mathrm{W}=85, \mathrm{p}=.164)$.

In Figure 4, we observed a significant association $(\mathrm{W}=24.5$, $\mathrm{p}=.036$ ) between POGIL use and "difficulty adapting teaching style" among highly trained individuals $(n=22)$. With regards to "difficulty adapting teaching style", the mean score for fifteen highly trained, high-use respondents was 1.73 , and the mean score for seven highly trained, low-use respondents was 2.71. This difference suggests that some highly

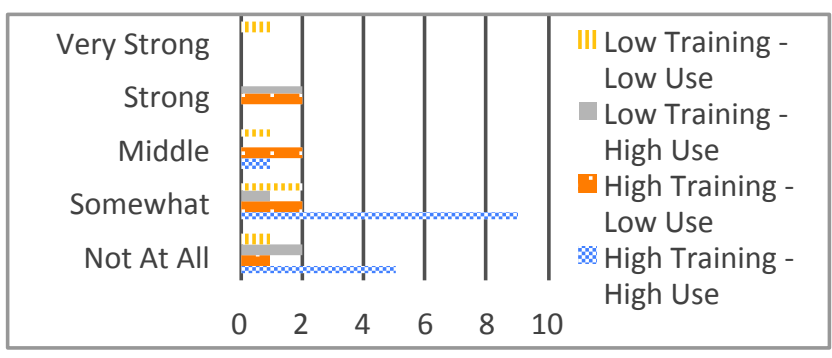

Figure 4: Difficulty adapting teaching style as a perceived obstacle to POGIL adoption $(n=32)$. Highlytrained instructors may refrain from adoption due to perceived difficulty in adapting their teaching style.

trained individuals may refrain from using POGIL because of difficulties associated with adapting their teaching style.

Six respondents mentioned classroom facilitation issues in their free-response answers about their main obstacles to implementing POGIL, including pacing the classroom experience, meeting the needs of students with prior knowledge, dealing with difficult students (both difficult personalities and difficult group dynamics), and "selling" POGIL to students ("hard to sell both Pair Programming and POGIL to the same group of students").

\subsection{Forms of Support}

In the last part of the survey, we asked faculty to estimate how "helpful would each of the following have been as you began to adopt POGIL, or if you have not tried POGIL, which do you think would be the most helpful if you decided to try it". Independent of prior training and current POGIL implementation, we observed interest in additional training and support. In free response questions, several suggested additional forms of support that were not mentioned in our survey (e.g., "videos of POGIL classes, to see more examples of facilitation", "more generic activities", and "a POGILized CS textbook").

$72 \%$ of respondents believed that "face-to-face meetings with other POGIL practitioners" would be somewhat, very, or extremely helpful, while $66 \%$ said the same for virtual meetings. For each respondent we looked at the difference between their response for face-to-face meetings and their response for virtual meetings, and recorded their comparative preference (face-to-face more helpful, virtual more helpful, or neutral). Figure 5 shows how the distribution is skewed $(\mathrm{V}=107, \mathrm{p}=.006) .44 \%$ prefer face-to-face, so the overall statistical significance is due to the opinions of a minority group. In free response questions, multiple respondents expressed an interest in mentorship and/or community, e.g., " a mentor to rely on for informal conversations" and "definitely more people to talk with regularly and share ideas for exercises."

Depending on the workshop topic, $59 \%$ to $75 \%$ of the respondents believed workshops would be somewhat, very, or extremely helpful. Some respondents preferred specialized workshops on POGIL classroom facilitation over general workshop training $(\mathrm{V}=110, \mathrm{p}=.102)$, and preferred specialized workshops on authoring POGIL activities over general workshop training $(\mathrm{V}=92, \mathrm{p}=.067)$. This could represent an overall desire for advanced training or two different areas of specific interest. High-use instructors were significantly more interested in facilitation over general workshops $(\mathrm{W}=170$, 


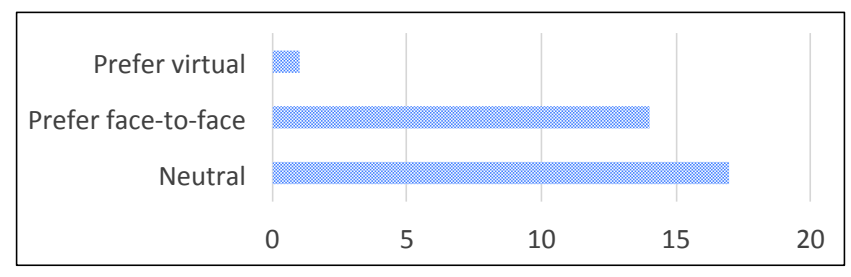

Figure 5: Regarding support, those with a preference desire face-to-face meetings over virtual meetings $(14: 1)$, but a majority $(n=17)$ lack a preference.

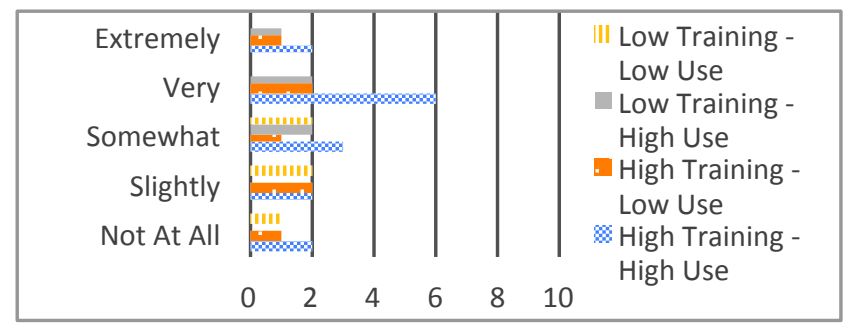

Figure 6: There is likely more interest in classroom observation among instructors with little training and high use of POGIL.

$\mathrm{p}=.038$ ), perhaps because they are more aware of the importance and difficulty of effective facilitation.

$69 \%$ of respondents believed classroom observations would be somewhat, very, or extremely helpful. Among the ten respondents with Low Training (see Section 2.1 for definitions, Figure 6 for graph), High Use instructors were significantly more interested in classroom observations $(\mathrm{W}=23, \mathrm{p}=.030)$. The authors have viewed this effect personally: instructors are hesitant about classroom observations until after they start to teach with POGIL and suddenly have more questions about classroom facilitation. The effect is less for respondents with High Training, perhaps because the three-day POGIL Regional Meeting includes a workshop that demonstrates the value of classroom observations.

\section{DISCUSSION}

Survey respondents generally agreed that POGIL had a positive effect on students in the classroom, especially by keeping them more engaged and active in learning (see Figure 1). We examined each of the 10 measures of POGIL effectiveness and found no associations for high versus low training or for high versus low use of POGIL. These findings support prior research showing that people do not adopt new instructional strategies because those strategies are effective $[8,13]$. Also, more training and more use did not appear to artificially inflate one's opinion of POGIL.

The greatest perceived obstacles included in the survey were lack of preparation time, availability of POGIL activities and pressure to cover more content. The results corroborate prior research that suggests that implementing active learning approaches faces similar barriers [30, 31]. Based on free responses, it seems possible that classroom time would rank high but this was not included in our survey. Most survey respondents did not perceive resistance to POGIL from colleagues or administrators to be an obstacle for adopting POGIL. The CS POGIL community could address these obstacles by improving the number of CS POGIL activities and standardizing them to make them easier to adopt by different instructors, possibly reducing the prep time.

Highly trained individuals with low POGIL use in their classrooms are a subpopulation of particular interest when considering barriers to faculty adoption. Based on Figure 4, we hypothesize that perceived time constraints are the major obstacle. Data for highly trained instructors is consistent with this hypothesis that it is a perceived lack of time that prevents some highly trained instructors from using POGIL. We compared time concerns among highly trained individuals and found an association with use $(\mathrm{W}=26.5, \mathrm{p}=.053)$, statistically insignificant possibly because of a smaller sample size $(n=22)$, but nonetheless indicative of a possible mechanism for workshop organizers to be aware of.

In addition to addressing perceived obstacles in future POGIL workshops, we can use the survey results to help shape additional support for faculty adopting POGIL. Most respondents were interested in additional workshops (especially classroom facilitation and activity writing workshops), meetings with other POGIL practitioners, and even classroom observations. Faculty unsurprisingly preferred faceto-face meetings to virtual meetings, but $53 \%$ exhibited no preference for the type of meeting, suggesting that some number of faculty would benefit from even less-costly, virtual meetings. Given the increased interest in classroom observations with POGIL use, we hypothesize that classroom observations should occur after new POGIL adopters have had the opportunity to use POGIL a few times in the classroom, when they have more experience to form questions.

Because the effectiveness and obstacle statements were adapted from a survey of faculty adopting case studies to teach undergraduate science [30], it is possible to compare our results with those from the original study of science faculty $(n=101)$. Responses from both studies had similar percentages for the effects on student engagement, peerto-peer relationships, and test performance. POGIL was perceived by the CS POGIL faculty as being more effective for communication skills, whereas case-studies were perceived by science faculty as being more effective for active learning and deeper understanding of concepts. On the other hand, more CS POGIL faculty than science faculty reported some difficulty with the obstacles listed in the survey.

In the future, we will continue surveying the CS POGIL community to expand on our results. We will extend the list of questions to address other process skills, obstacles, and forms of support. It would be useful to replicate this survey with other (larger) populations in POGIL and other evidencebased strategies, to be able to compare benefits, obstacles, and support options across disciplines and strategies.

From a practical perspective, the results of this survey suggest ways to help more instructors adopt POGIL. Since preparation time, classroom time, and availability of activities are perceived barriers, POGIL workshops should be revised to more explicitly address these concerns. Similarly, additional sets of POGIL activities should be developed and enhanced to facilitate adoption and reduce the time required for adaptation. At least some instructors new to POGIL would benefit from more post-workshop support, such as classroom observations and other mentoring. 


\section{ACKNOWLEDGMENTS}

This material is based upon work supported by National Science Foundation Grant DUE-1044679, a Google CS4HS grant, multiple Google CS Engagement grants, and a grant from the AAC\&U TIDES Institute and the Leona M. and Harry B. Helmsley Charitable Trust.

\section{REFERENCES}

[1] L. Beck and A. Chizhik. Cooperative Learning Instructional Methods for CS1: Design, Implementation, and Evaluation. ACM Transactions on Computing Education, 13(3):10:1-10:21, 2013.

[2] M. Borrego, S. Cutler, M. Prince, C. Henderson, and J. E. Froyd. Fidelity of Implementation of Research-Based Instructional Strategies (RBIS) in Engineering Science Courses. Journal of Engineering Education, 102(3):394-425, 2013.

[3] S. E. Brownell and K. D. Tanner. Barriers to Faculty Pedagogical Change: Lack of Training, Time, Incentives, and...Tensions with Professional Identity? CBE-Life Sciences Education, 11(4):339-346, 2012.

[4] A. F. Chávez. Toward a Multicultural Ecology of Teaching and Learning: A Critical Review of Theory and Research. Journal on Excellence in College Teaching, 21(4):49-74, 2011.

[5] M. T. H. Chi and R. Wylie. The ICAP Framework: Linking Cognitive Engagement to Active Learning Outcomes. Edu. Psychologist, 49(4):219-243, 2014.

[6] E. P. Douglas and C.-C. Chiu. Implementation of Process Oriented Guided Inquiry Learning (POGIL) in Engineering. Adv. in Eng. Edu., 3(3):1-15, 2013.

[7] J. J. Farrell, R. S. Moog, and J. N. Spencer. A Guided-Inquiry General Chemistry Course. Journal of Chemical Education, 76(4):570-574, 1999.

[8] S. Fincher, B. Richards, J. Finlay, H. Sharp, and I. Falconer. Stories of Change: How Educators Change Their Practice. In Frontiers in Edu. Conf., 2012.

[9] L. Gafney and P. Varma-Nelson. Peer-Led Team Learning: Evaluation, Dissemination, and Institutionalization of a College Level Initiative. Springer Science \& Business Media, 2008.

[10] D. M. Hanson. Instructor's Guide to Process-Oriented Guided-Inquiry Learning. Pacific Crest, 2006.

[11] T. Hemraj-Benny and I. Beckford. Cooperative and Inquiry-Based Learning Utilizing Art-Related Topics: Teaching Chemistry to Community College Nonscience Majors. Journal of Chemical Education, 91(10):1618-1622, 2014.

[12] C. Henderson, A. Beach, and N. Finkelstein. Facilitating Change in Undergraduate STEM Instructional Practices: An Analytic Review of the Literature. Journal of Research in Science Teaching, 48(8):952-984, 2011.

[13] C. Henderson, M. Dancy, and M. NiewiadomskaBugaj. Use of Research-Based Instructional Strategies in Introductory Physics: Where Do Faculty Leave the Innovation-Decision Process? Phys. Rev. ST Phys. Educ. Res., 8(2):020104, 2012.

[14] T. B. Higgins. Teaching Chemistry with POGIL at an Urban, Minority-Serving Community College. In Abs. of Papers of The American Chemical Society, 2013.
[15] S. Horwitz, S. H. Rodger, et al. Using Peer-Led Team Learning to Increase Participation and Success of Under-Represented Groups in Introductory Computer Science. ACM SIGCSE Bulletin, 41(1):163-167, 2009.

[16] H. Hu and B. Avery. CS Principles with POGIL Activities As a Learning Community. Journal of Computing Sciences in Colleges, 31(2):79-86, 2015.

[17] H. H. Hu and T. D. Shepherd. Teaching CS 1 with POGIL Activities and Roles. In Proceedings of the 45th ACM Tech. Sym. on CS Education, 2014.

[18] C. D. Hundhausen, A. Agrawal, and P. Agarwal. Talking About Code: Integrating Pedagogical Code Reviews into Early Computing Courses. ACM Trans. on Computing Education, 13(3):14:1-14:28, 2013.

[19] C. D. Hundhausen, N. H. Narayanan, and M. E. Crosby. Exploring Studio-Based Instructional Models for Computing Education. SIGCSE Bulletin, 40(1):392-396, 2008.

[20] A. Kezar. What Is the Best Way to Achieve Broader Reach of Improved Practices in Higher Education? Innovative Higher Education, 36(4):235-247, 2011.

[21] S. Kumar and C. Wallace. Instruction in Software Project Communication through Guided Inquiry and Reflection. In IEEE Frontiers in Edu. Conf., 2014.

[22] C. B. Lee, S. Garcia, and L. Porter. Can Peer Instruction Be Effective in Upper-division Computer Science Courses? ACM Transactions on Computing Education, 13(3):12:1-12:22, 2013.

[23] L. Lenz. Active Learning in a Math for Liberal Arts Classroom. PRIMUS, 25(3):279-296, 2015.

[24] R. Moog. Integrating Cognitive Science with Innovative Teaching in STEM Disciplines, chapter Process Oriented Guided Inquiry Learning, pages 147-166. Washington University Open Scholarship, 2014.

[25] R. S. Moog and J. N. Spencer, editors. Process-Oriented Guided Inquiry Learning (POGIL). American Chemical Society, 2008.

[26] M. Rutten. A POGIL Approach to Teaching Engineering Hydrology. In American Geophysical Union Fall Meeting Abstracts, 2012.

[27] N. Salleh, E. Mendes, and J. Grundy. Empirical Studies of Pair Programming for CS/SE Teaching in Higher Education: A Systematic Literature Review. IEEE Trans. on Software Eng., 37(4):509-525, 2011.

[28] B. Simon and Q. Cutts. Peer Instruction: A Teaching Method to Foster Deep Understanding. Communications of the ACM, 55(2):27-29, 2012.

[29] T. Vanags, K. Pammer, and J. Brinker. Process-Oriented Guided-Inquiry Learning Improves Long-Term Retention of Information. Advances in Physiology Education, 37(3):233-241, 2013.

[30] A. Yadav, M. Lundeberg, et al. Teaching Science with Case Studies: A National Survey of Faculty Perceptions of the Benefits and Challenges of Using Cases. Journal of College Science Teaching, 37(1):34-38, 2007.

[31] A. Yadav, G. M. Shaver, and P. Meckl. Lessons Learned: Implementing the Case Teaching Method in a Mechanical Engineering Course. Journal of Engineering Education, 99(1):55-69, 2010. 